\title{
Educação em tempos de covid-19 e o ensino remoto emergencial: o que dizem os professores da Escola Municipal José Ribeiro Bessa?
}

\author{
Education in Covid-19 times and the emergencial remote teaching: what do \\ teachears of Escola Municipal José Ribeiro Bessa say?
}

Evelyn Fernandes Azevedo Faheina Doutorado em Educação/UFPB Universidade Federal da Paraíba - UFPB. João Pessoa, Paraíba - Brasil. evelynfaheina@gmail.com

Agnes Camila Viana da Silva Licenciatura em Pedagogia

Universidade Federal da Paraíba - UFPB. Mataraca, Paraíba - Brasil. agnes.camila@gmail.com

\begin{abstract}
Resumo: Este artigo comunica os resultados de uma investigação que buscou conhecer como os professores, que lecionam do $3^{\circ}$ ao $5^{\circ}$ ano do Ensino Fundamental, da Escola Municipal José Ribeiro Bessa, localizada no município de Mataraca-PB, utilizam recursos tecnológicos durante o Ensino Remoto Emergencial (ERE). Para tanto, recorreu ao debate teórico proposto por Palú, Schütz e Mayer (2020), Caetano, Junior e Teixeira (2020), Behrens (2013) e Pareceres emitidos pelo Conselho Nacional de Educação, CNE/CP: n 5 (BRASIL, $2020 \mathrm{a}), \mathrm{n}^{\circ} 15$ (BRASIL, 2020b), n ${ }^{\circ} 6$ (BRASIL, 2021a) e no 2 (BRASIL, 2021b). A técnica utilizada para a coleta de dados foi o questionário, cujas informações foram apreciadas à luz da análise de conteúdo (BARDIN, 2016). A pesquisa indica que as dificuldades de acesso à internet por estudantes, a necessidade de adaptação e superação ao ERE por professores, acentuam os processos de exclusão social já existentes, a precarização do trabalho docente e a qualidade da educação ofertada.
\end{abstract}

Palavras chave ensino remoto emergencial; pandemia da Covid-19; atuação docente.

Abstract: This article presents the results of an investigation that knew how the teachers - that work with 3rd and 5th years, in Elementary school, at Escola Municipal José Ribeiro Bessa, in Mataraca - Paraíba, Brazil - used the technological resources during the Emergencial Remote Teaching (ERT). Thus, we used the theoretical references grounded by Palú, Schütz and Mayer (2020), Caetano, Junior and Teixeira (2020), Behrens (2013) and the delivered opinion by the Conselho Nacional de Educação, CNE/CP: number 5 (BRASIL, $2020 \mathrm{a}$ ), number 15 (BRASIL, 2020b), number 6 (BRASIL, 2021a) and number 2 (BRASIL, 2021b). Questionnaire is the technique used to collect data, and the information was verified in accordance with the analysis content (BARDIN, 2020). This research indicates that the difficulties related to the internet access by the students, the need of adaptation and overcoming of ERT by teachers, emphasize the social execution processes already existed, the teaching precariousness and the offered education quality.

Keywords: emergencial remote teaching; Covid-19 pandemic; teaching acting.

Cite como

\section{(ABNT NBR 6023:2018)}

FAHEINA, Evelyn Fernandes Azevedo; SILVA, Agnes Camila Viana. Educação em tempos de Covid-19 e o ensino remoto emergencial: o que dizem os professores da Escola Municipal José Ribeiro Bessa? Dialogia, São Paulo, n. 40, p. 1-18, e20853, jan./abr. 2022. Disponível em: https://doi.org/10.5585/40.2022.20853.

American Psychological Association (APA)

Faheina, E. F. A., \& Silva, A. C. V. (2022, jan./abr.) Educação em tempos de Covid-19 e o ensino remoto emergencial: o que dizem os professores da Escola Municipal José Ribeiro Bessa?. Dialogia, São Paulo, 40, p. 1-18, e20853. https://doi.org/10.5585/40.2022.20639. 


\section{Introdução}

Com o surgimento da pandemia da covid-19, identificada pela primeira vez em Wuhan, na China, em dezembro de 2019, uma série de medidas foram adotadas no Brasil e no mundo no tocante à abertura e a realização de atividades comerciais, educacionais, culturais e sociais. As autoridades de saúde de todos os países afetados recomendaram o isolamento social como estratégia para conter o contágio da população mundial, e determinaram em alguns momentos/meses dos anos 2020/2021 o fechamento (parcial ou total) de empresas, escolas, universidades e vários setores considerados não essências, como parques e praias, para evitar aglomerações. Em casos mais extremos, onde o índice de mortes por covid-19 foi considerado elevado, as autoridades decretaram o lockdown ${ }^{1}$, recomendando o isolamento da população em suas casas e o fechamento quase total do comércio e de alguns serviços considerados essenciais como escolas e universidades (PORTAL DO GOVERNO BRASILEIRO, 2020).

Em face desse cenário, e na tentativa inevitável de buscar soluções à dimensão de urgência acionada pela pandemia da covid-19, as atividades escolares presencias dos estabelecimentos de ensino, como creches, escolas e universidades, foram suspensas, pois considerou-se, essa, uma medida essencial para evitar a propagação do vírus, justificando-se, por outra via, a necessidade de implementação do Ensino Remoto Emergencial (ERE) para as redes de ensino, de todos os níveis, etapas e modalidades. Tais orientações permaneceram até o final do segundo semestre de 2021, em conformidade com o parecer CNE/CP publicado em 6 de julho de 2021 (BRASIL, 2021b).

$\mathrm{Na}$ escola Municipal José Ribeiro Bessa, localizada no município de Mataraca-PB que, em particular, constituiu o campo de nossa ação investigativa, cujos resultados estão comunicados no presente texto, verificou-se a oferta de ensino totalmente remoto, de maio de 2020 a agosto de 2021, disponibilizando aos estudantes atividades impressas que deveriam ser respondidas e compartilhadas com os professores, através do WhatsApp. A partir de setembro de 2021, a escola adotou o ensino totalmente híbrido, em consonância com a Resolução CNE/CP n $n^{\circ}$ 2/2021 (BRASIL, 2021b), que estabelece as diretrizes nacionais para o retorno à presencialidade das atividades de ensino e aprendizagem, e das orientações previstas na Nota Técnica no 01/2021 da Secretaria de Educação e Desporto do município de Mataraca-PB (SECRETARIA DE EDUCAÇÃO E DESPORTO, 2021).

${ }^{1}$ Estados brasileiros que decretaram lockdown: https://www.melhoresdestinos.com.br/restricoes-estado-brasil-quarentena.html. (ESTADO, 2020). 
De modo mais específico, a pesquisa buscou investigar como os professores ${ }^{2}$, que lecionam do $3^{\circ}$ ao $5^{\circ}$ ano do Ensino Fundamental, na referida escola, utilizaram recursos tecnológicos em sua prática docente durante o ERE. Nesse sentido, esta proposta objetiva comunicar os resultados da investigação, cujas informações foram obtidas através da aplicação de um questionário com os professores e apreciados à luz da análise de conteúdo (BARDIN, 2016) com o intuito de refletir, em diálogo com outros autores ${ }^{3}$ e documentos legais ${ }^{4}$, sobre a adoção do ERE e seus impactos na educação.

Sem a pretensão de encerrar qualquer possibilidade de análise que a temática em foco requer, parece-nos razoável afirmar que o entendimento que temos sobre o ERE precisa considerar, minimamente, o confronto com as ideias que permeiam o senso comum em torno de certo "fetichismo" com relação ao uso de tecnologias na educação, como se seu uso em larga escala, em si, fosse capaz de promover grandes resultados. Ademais, parece-nos ingênuo pensar que o apelo ideológico modernizador do ERE, mediado pelo uso massificante de plataformas, recursos e redes sociais, seja concebido como a única alternativa para atender à complexa realidade epidemiológica associada ao necessário distanciamento social ${ }^{5}$.

Em nosso ponto de vista, a simples adaptação dos profissionais de educação ao ERE, que, na maioria das vezes, concebem com grande entusiasmo e otimismo o uso de certos aparatos tecnológicos, necessitam ser analisados à luz das mudanças que envolvem o trabalho docente, da necessidade de reflexão/formação continuada ou, ainda, da crítica à precarização do serviço humano ofertado que, por vezes, precisa empreender e custear suas próprias condições de trabalho, como a disponibilização de acesso à internet e a recursos tecnológicos demandados pelo ERE.

O texto está organizado em três seções principais. Na primeira, apresentamos uma breve discussão sobre o cenário educacional no contexto epidemiológico da covid-19 (2020-2021), especificamente, sobre o ERE, que passou a ser ofertado nas escolas de Educação Básica e Superior públicas brasileiras como uma medida essencial para evitar a propagação e a contaminação do vírus SARS-Cov-2 desde o primeiro semestre de 2020. Na segunda seção, explicitamos os procedimentos metodológicos da pesquisa, com destaque à indicação das razões que orientaram a

\footnotetext{
${ }^{2}$ Utilizamos o termo "professores" para nos referir a todos os(as) docentes que colaboraram com a pesquisa, respondendo ao questionário. Vale salientar, também, que está investigação orienta-se por abordagens e instrumentos metodológicos que obedeceram aos procedimentos éticos estabelecidos para a pesquisa científica, em Ciências Humanas.

${ }^{3}$ Palú, Schutz e Mayer (2020); Caetano, Junior e Teixeira (2020); Martins e Almeida (2020); Sampaio e Leite (2013); Behrens (2013).

${ }^{4}$ Brasil $(2013 ; 2018 ; 2020 \mathrm{a} ; 2020 \mathrm{~b} ; 2020 \mathrm{c} ; 2021)$.

${ }^{5}$ Vale salientar que outras medidas foram adotadas para conter o avanço da epidemia, a exemplo da aplicação de vacinas, cujo processo pode ser acompanhado nacionalmente através do site https://www.gov.br/saude/pt-br/vacinacao?, e as diretrizes orientadoras para implementação de medidas no retorno à presencialidade das atividades de ensino e aprendizagem, publicadas pelo Conselho Nacional de Educação (CNE), em 6 de julho e 5 de agosto de 2021, respectivamente (BRASIL, 2021a, 2021b).
} 
escolha dos instrumentos e da técnica de análise dos dados. Finalmente, na terceira, conferimos visibilidade aos resultados e discussões que envolveram a pesquisa.

\section{O cenário educacional frente a pandemia da covid-19: o ensino remoto como alternativa?}

Em 28 de abril de 2020, em colaboração com o Ministério da Educação ${ }^{6}$ (MEC), o Conselho Nacional de Educação (CNE) publicou um Parecer (BRASIL, 2020a) apontando algumas diretrizes às instituições de Educação Básica e de Ensino Superior quanto ao enfrentamento à pandemia da covid-19. Uma delas consistiu na indicação do uso de recursos tecnológicos, plataformas digitais e redes sociais, além de programas de televisão, rádio e material didático impresso, para ser entregue aos pais e/ou responsáveis dos estudantes, com o objetivo de dar continuidade ao processo de ensino e aprendizagem escolar não presencial (BRASIL, 2020a).

Para dar suporte a essa propositura, o MEC também disponibilizou, através da Plataforma AVAMEC $^{7}$, diversos cursos on-line com temáticas variadas a fim de propiciar formação continuada para professores, gestores e toda a comunidade escolar/acadêmica. Das recomendações voltadas para os anos iniciais do Ensino Fundamental, consta a sugestão de orientação às famílias no tocante ao manuseio e a disponibilização de plataformas digitais que permitissem o acompanhamento das atividades realizadas pelos estudantes durante o ERE. Sendo assim, o MEC recomendou aos sistemas de ensino que:

No período de afastamento presencial, as escolas orientassem alunos e famílias a fazer um planejamento de estudos, com o acompanhamento do cumprimento das atividades pedagógicas não presenciais por mediadores familiares (BRASIL, 2020b, grifo nosso, p. 9).

Com isso, o cenário educacional que se apresenta, desde 2020, no enfrentamento à pandemia da covid-19 é a de:

Vídeos, conferências on-line, mensagens, lives, áudios, imagens e sons, tudo junto e misturado. Professores, alunos e seus responsáveis, criando em tempo recorde táticas de sobrevivência a uma demanda de ensino, muitas vezes massivo e unidirecional, o chamado ensino remoto. (MARTINS; ALMEIDA, 2020, p. 219).

A expressão "Ensino Remoto" ou "Ensino Remoto Emergencial” (ERE) vem sendo utilizada na literatura brasileira para se referir aos processos nos quais operou-se a modificação do ensino totalmente presencial para o remoto. Tal realidade, entretanto, parece-nos estar com seus

\footnotetext{
${ }^{6}$ Confira: Ministério da Educação, 2020.

${ }^{7}$ Para mais informações, consulte: https://avamec.mec.gov.br/.
} 
dias contados. O avanço da aplicação de imunizantes "anticovid" e o último Parecer do CNE/CP, publicado em 5 de agosto de 2021, estabelecendo as diretrizes nacionais para implementação de medidas ao retorno da presencialidade das atividades escolares, a partir do segundo semestre de 2021, podem ser apontadas como um possível encerramento do ensino totalmente remoto para o presencial e/ou híbrido (BRASIL, 2021b).

Enquanto ainda caminhamos para tal realidade, é importante entender que o ensino remoto se diferencia da Educação a Distância $(\mathrm{EaD})$ na medida em que essa última é considerada uma modalidade de ensino, na qual, está prevista a mediação dos processos de ensino e aprendizagem com o uso de meios e Tecnologias Digitais da Informação e Comunicação (TDIC), “[...] com pessoal qualificado, com políticas de acesso, com acompanhamento e avaliação compatíveis" (BRASIL, 2017, p. 3). Além disso, difere-se por ser entendida como uma modalidade complementar ao Ensino Fundamental presencial, uma vez que essa etapa da Educação Básica, de acordo com a última atualização da Lei de Diretrizes e Bases da Educação Nacional (LDBEN), no art. 32, inciso IV, publicada em 2020, o ensino a distância poderá ser "utilizado como complementação da aprendizagem ou em situações emergenciais” (BRASIL, 2020c, p. 24). Por razões como essas:

\begin{abstract}
Não se pode confundir educação a distância $(\mathrm{EaD})$ com atividade remota pela internet em situação de crise grave. EaD é toda uma concepção didática e de estudo e aprendizagem que envolve estrutura, conteúdos, formação e que abrange desde o desenho didático inicial adequado às características da área de conhecimento específica até as avaliações da aprendizagem discente, executada por equipe multidisciplinar treinada. [...]. Atividade remota é fazer alguma atividade temporária via internet, em situações precárias e emergenciais, para tentar reduzir danos da aprendizagem a partir de um sistema de ensino originalmente presencial (JUNQUEIRA, 2020, p. on-line).
\end{abstract}

Posto dessa forma, entende-se que o ERE é uma expressão utilizada eventualmente na literatura para se referir a processos de ensino e aprendizagem estabelecidos de forma remota, em virtude das circunstâncias provocadas pela pandemia da covid-19. No ERE, a aula acontece de modo síncrono, entre professor e aluno, seguindo os princípios do ensino presencial, com videoaulas, exposição de conteúdos pelo professor via web-conferência, assim como encaminhamentos de atividades para serem realizadas pelos estudantes em um Ambiente Virtual de Aprendizagem (AVA) que acontece de modo assíncrono.

De um lado, isso nos interpela, conforme registra Caetano, Junior e Teixeira, a "refletir sobre as possibilidades de acesso à internet e, principalmente, sobre as condições que os/as estudantes possuem para acessar a rede" (CAETANO; JUNIOR; TEIXEIRA, 2020, p. 124), pois sabemos que existem alguns grupos sociais, especialmente alunos oriundos de escolas públicas, que 
não dispõem de recursos ou meios tecnológicos mínimos para continuar seus estudos de forma remota (MARTINS; ALMEIDA, 2020). Ademais, conforme sinaliza Dias e Pinto (2020), o acesso às tecnologias por parte dos alunos da rede pública de ensino geralmente é feito por meio de celulares, compartilhados com outros membros da família, e o acesso a computadores ou internet para realização de atividades, síncronas ou assíncronas, ainda não corresponde à realidade da maioria dos estudantes brasileiros.

Além da dificuldade relacionada ao acesso às tecnologias, muitas famílias também têm apresentado o obstáculo em acompanhar as atividades de seus filhos:

\begin{abstract}
Algumas podem ajudar seus filhos a aprender mais do que outras. Fatores como a quantidade de tempo disponível para se dedicar aos estudos dos filhos, auxiliando-os com as aulas online - muitos pais estão em home office cumprindo horário laboral integral e outros tantos precisam trabalhar externamente para garantir a renda mensal -; as habilidades não cognitivas dos genitores; a possibilidade de acessar o material online; a quantidade de conhecimento inato dos pais - afinal, é difícil ajudar o filho se tiver de aprender algo estranho ao que se conheceu e aprendeu - , são questões a serem levados em conta quanto ao papel dos pais na Educação dos filhos em tempos de pandemia. Toda essa situação gerará um aumento da desigualdade na Educação e no progresso do estudante. (DIAS; PINTO, 2020, p. 547).
\end{abstract}

Nesse sentido, o acompanhamento das atividades dos estudantes, por parte das famílias, não ocorre: seja porque elas estão trabalhando enquanto seus filhos assistem às aulas síncronas ou porque os pais não compreendem os conteúdos estudados pelos filhos na escola.

Por outro lado, o ERE que acontece no atual cenário epidemiológico, leva-nos a refletir sobre os processos formativos ou a ausência deles na formação dos professores, que antes atuavam no ensino totalmente presencial e migraram, circunstancialmente, para o ensino remoto.

[...] um número considerável alto de professores precisou aprender a utilizar as plataformas digitais, inserir atividades online, avaliar os estudantes a distância e produzir e inserir nas plataformas material que ajude o aluno a entender os conteúdos, além das usuais aulas gravadas e online. $\mathrm{Na}$ pandemia, grande parte das escolas e das universidades estão fazendo o possível para garantir o uso das ferramentas digitais, mas sem terem o tempo hábil para testá-las ou capacitar o corpo docente e técnico-administrativo para utilizá-las corretamente. (DIAS; PINTO, 2020, p. 546).

Em face disso, percebemos várias dificuldades enfrentadas durante o ERE, tanto por parte dos professores, que precisaram (re)pensar sua prática docente e formas de avaliação pautadas nas tecnologias digitais, quanto por alunos, no tocante à dificuldade de acesso à internet e o acompanhamento das aulas síncronas, visto que, a maioria deles, não dispõe de recursos e meios tecnológicos necessários. 


\section{Aspectos metodológicos}

As discussões sobre a utilização de tecnologias durante o ERE devem ser tratadas no âmbito da investigação científica, com foco voltado à produção de conhecimento. Em vista disso, inicialmente, fizemos uma revisão de literatura sobre a temática central da pesquisa (PALÚ; SCHÜTZ; MAYER, 2020; CAETANO; JUNIOR; TEIXEIRA, 2020; MARTINS; ALMEIDA, 2020; SAMPAIO; LEITE, 2013; BEHRENS, 2013; BRASIL, 2013, 2018, 2020a, 2020b, 2020c, 2021a, 2021b). No segundo momento, entramos em contato com a Escola Municipal de Ensino Fundamental José Ribeiro Bessa, localizada no município de Mataraca-PB.

Escolhemos a referida instituição para o desenvolvimento da investigação por ser a única da cidade a ofertar os anos iniciais do Ensino Fundamental, em particular, turmas do $3^{\circ}$ ao $5^{\circ}$ ano, objeto da pesquisa. Assim, na primeira visita à escola, apresentamos nossas intenções à gestora escolar e aos professores, e coletamos informações prévias sobre como a instituição está promovendo o ERE. De acordo com as informações obtidas, constatamos que a escola ofertou o ensino totalmente remoto de maio de 2020 a agosto de 2021 e, nesse período, disponibilizou aos estudantes atividades em apostilas que deveriam ser respondidas e compartilhadas com os professores através do Whats $A p p$.

Para a coleta de dados, utilizamos como instrumento o questionário, elaborado através do Google Forms e enviado pelo Whats App para os professores, sujeitos da pesquisa. Dos 19 professores que receberam o questionário, apenas 18 responderam. Quanto à elaboração das questões, consideramos somente aquelas que estabeleciam relação com os objetivos específicos da pesquisa. Assim, no total, foram formuladas 17 perguntas, sendo 11 objetivas e 6 subjetivas. Além disso, vale salientar que, em função da estratégia de pesquisa adotada, não foi realizado nenhum trabalho de observação com a intenção de complementar ou confrontar as informações dos questionários aplicados.

A técnica utilizada para apreciação dos dados foi a análise de conteúdo, proposta por Laurence Bardin (2016), que implica um "[...] conjunto de técnicas de análise das comunicações que utiliza procedimentos sistemáticos e objetivos de descrição do conteúdo das mensagens" (BARDIN, 2016, grifo da autora, p. 44). Sendo assim, com os dados em mãos, observamos, também, a frequência que alguns indicadores apareciam nas respostas dos professores, contudo, o foco estava na presença do indicador e não na frequência em cada resposta analisada.

Nesse tipo de análise, o processo é compreendido por algumas etapas: a organização, na qual é realizado o processo de exploração do material, atribuindo-lhes a interpretação dos resultados obtidos; a codificação, na qual é realizado a transformação dos dados em números para 
que se possa atingir uma representação dos conteúdos; a categorização, que consiste na classificação dos elementos constitutivos de um conjunto por diferenciação, a qual, em seguida, é reagrupada de acordo com critérios previamente definidos; e a inferência que diz respeito à dedução de um resultado com base na interpretação de informações baseadas nas respostas dos professores aos questionários aplicados (BARDIN, 2016).

Dentre as diversas técnicas da Análise de Conteúdo, optou-se pela análise temática que se refere à “[...] contagem de um ou vários temas ou itens de significação, numa unidade de codificação previamente determinada" (BARDIN, 2016, p. 77). Vale ressaltar, ainda, que a intenção da análise de conteúdo é "a inferência de conbecimentos relativos às condições de produção (ou, eventualmente, de recepção), inferência esta que recorre a indicadores (quantitativos ou não)" (BARDIN, 2016, grifo da autora, p. 44).

Assim, apoiando-se nesses pressupostos investigativos, que direcionam a pesquisa de forma planejada, intencionamos conhecer como os professores que estavam lecionando nas turmas do $3^{\circ}$ ao $5^{\circ}$ ano, na Escola Municipal de Ensino Fundamental José Ribeiro Bessa, no período de maio de 2020 a agosto de 2021, estavam conduzindo o ERE com o uso de Tecnologias Digitais da Informação e Comunicação (TDIC). Para tanto, analisamos todas as informações que foram coletadas através do questionário aplicado.

No processo de sistematização dos dados, identificamos os professores por letras do alfabeto, mantendo-os em anonimato, e organizamos suas respostas em forma de gráficos e quadros. Porém, para esta comunicação mais sintética da pesquisa, optamos por apresentar apenas os percentuais do quantitativo de respostas dadas a determinada questão, alguns gráficos e um dos quadros que sistematiza a opinião dos professores com relação a ausência ou a insuficiência de formação ofertada no período remoto emergencial de maio de 2020 a agosto de 2021.

\section{Análises e resultados}

A partir da análise do conteúdo dos questionários aplicados com os professores, verificamos que as aulas estavam sendo realizadas de forma totalmente remota (100\%), de maio de 2020 a agosto de 2021, tendo adotado o ensino híbrido somente a partir de setembro de 2021 sob as orientações da Nota Técnica no 01/2021, da Secretaria de Educação e Desporto do município de Mataraca-PB, e da Resolução CNE/CP nº 2, de 5 de agosto de 2021, que estabelece as diretrizes nacionais para o retorno à presencialidade das atividades de ensino e aprendizagem. Tal realidade esteve alinhada ao contexto educacional do país, no qual dois terços dos seus municípios $(92 \%)$ 
funcionaram, apenas, de forma remota, enquanto $8,1 \%$ adotaram o ensino híbrido ${ }^{8}$, no mesmo período de 2020 a 2021 (INSTITUTO UNIBANCO, 2021, p. on-line).

Quando questionados sobre o suporte material que a escola oferecia para o desenvolvimento do ERE, os professores responderam que os materiais impressos foram os mais utilizados. Dezessete (17) deles afirmaram que a escola ofereceu apostilas aos estudantes e 1 respondeu que a escola não disponibilizou nenhum material didático, conforme registra o gráfico a seguir. Além disso, os docentes relataram que não receberam apoio da escola no tocante à disponibilidade de recursos tecnológicos para o desenvolvimento de suas aulas, ficando à seu critério e custas a aquisição de materiais que lhes fossem apropriados.

Gráfico 1 - Como a escola tem dado o suporte para o desenvolvimento das aulas remotas

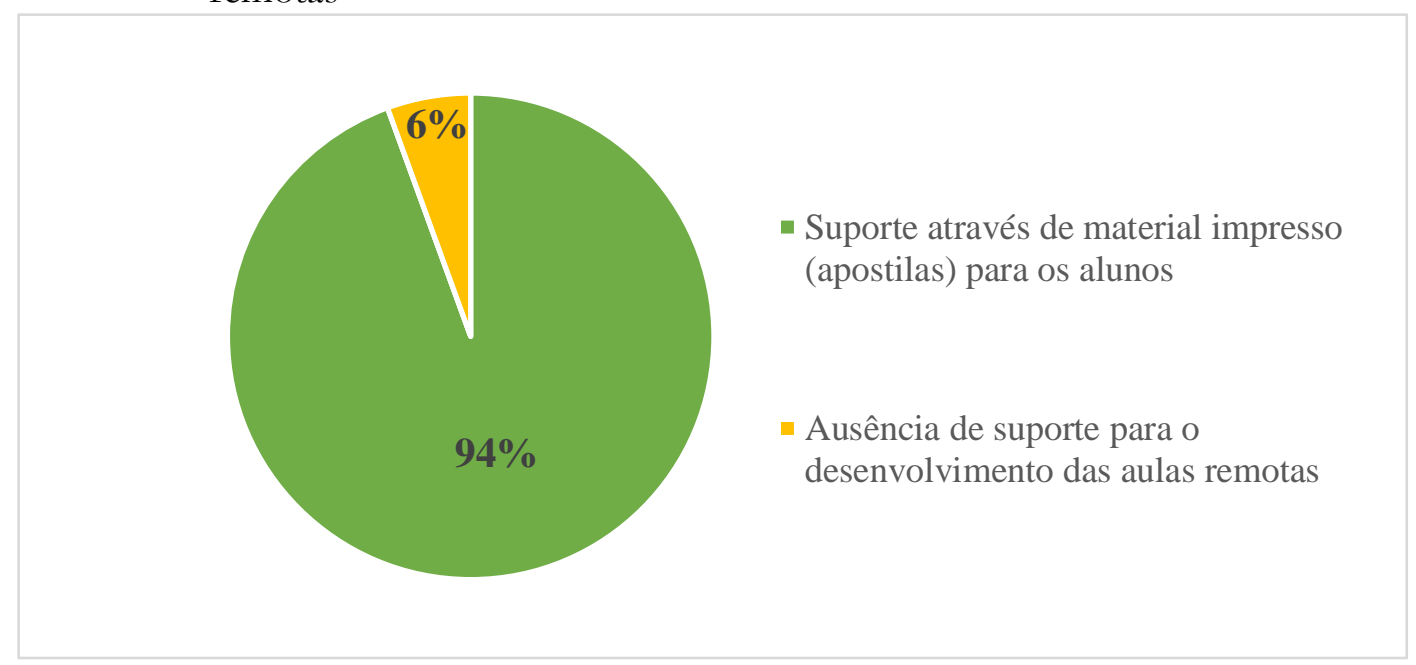

Fonte: As autoras, 2021.

Com efeito, tal realidade confirma os resultados da pesquisa desenvolvida por Palú, Schütz e Mayer (2020), que indicaram o uso de TDIC ou atividades impressas como os recursos e/ou materiais mais adotados pelos estados brasileiros em 2020 durante o ERE. Além disso, e de modo particular, o Conselho Nacional de Secretários de Educação (CONSED/2021) ${ }^{9}$, através da secretaria do Estado da Paraíba, lançou a Plataforma "Paraíba Educa"10 e firmou parcerias para exibição de teleaulas pela TV Assembleia como forma de subsidiar o processo de ensino e aprendizagem desde 2020.

\footnotetext{
${ }^{8}$ Pesquisa divulgada no Parecer CNE, em 6 de julho de 2021 (BRASIL, 2021a).

${ }_{9}^{9}$ Acesse a página do CONSED (http://www.consed.org.br/central-de-conteudos-estados/list/PB) e consulte os procedimentos adotados pelas secretarias de cada estado brasileiro frente à realização de atividades durante o ERE.

${ }^{10}$ Confira: https://sites.google.com/prod/see.pb.gov.br/pbeduca.
} 
No tocante à formação de professores voltada à temática do ERE, $61 \%$ responderam que não tiveram formação, $28 \%$ que lhes foram ofertadas, mas de forma insuficiente, e 11\% afirmaram que receberam formação adequada com relação ao manuseio de tecnologias durante o ensino remoto. Para aqueles que apontaram ausência de formação ou oferta insuficiente, os professores registraram as seguintes respostas:

Quadro 1 - Razões que indicam ausência de formação ou esta ofertada ocorre de forma insuficiente

\begin{tabular}{|c|l|}
\hline PROFESSOR(A) & \multicolumn{1}{|c|}{ RESPOSTAS } \\
\hline Professora A & $\begin{array}{l}\text { "Faltou não só ficar na teoria, mas ir para } \\
\text { prática, visto que muitos professores ainda } \\
\text { sentem dificuldade para lidar com alguns } \\
\text { aplicativos." }\end{array}$ \\
\hline Professora B & $\begin{array}{l}\text { "Ter um acompanhamento melhor com o } \\
\text { professor, dar mais suporte!" }\end{array}$ \\
\hline Professora C & "Não teve ainda nem uma formação." \\
\hline Professor D & $\begin{array}{l}\text { "Não tenho maiores informações, cheguei a } \\
\text { pouco tempo na rede municipal." }\end{array}$ \\
\hline Professor E & "Faltou a formação." \\
\hline Professora F & $\begin{array}{l}\text { "Na verdade comecei com a turma há poucos } \\
\text { dias, mas a escola não responde a meus } \\
\text { questionamentos e muito menos me dá } \\
\text { suporte para compreender a situação dos } \\
\text { meus alunos." }\end{array}$ \\
\hline "Tudo, pois não houve formação, fui \\
aprendendo pelos meus próprios esforços é \\
apoio de colegas de trabalho."
\end{tabular}

Fonte: As autoras, 2021.

Em face do quadro de respostas apresentadas pelos professores em relação à formação que lhes foi ofertada pela escola, observamos a indicação de formação continuada com o objetivo de 
lhes prepararem para a prática do "como fazer e utilizar" recursos tecnológicos digitais no contexto do ensino remoto. Identificamos, também, que recebendo ou não formação, os professores têm se apropriado de tecnologias durante o contexto epidemiológico da covid-19, sendo desafiados a lidar com diferentes recursos e a avaliar como, porquê e quando devem ser utilizados nos processos educativos escolares (SAMPAIO; LEITE, 2013).

A perspectiva que se apresenta é que o professor assuma o papel de mediador pedagógico e facilitador do conhecimento, e não simples transmissor, pois um dos grandes desafios consiste exatamente em mudar a concepção de ensinar para promover nos alunos caminhos que os levem a aprender e a construir seu próprio conhecimento. Assim, como afirma Behrens, "A tecnologia precisa ser contemplada na prática pedagógica do professor, a fim de instrumentalizá-lo a agir e interagir no mundo com critério, com ética e com visão transformadora" (2013, p. 79). Não obstante, vale lembrar que, com uma formação adequada, possivelmente os professores se sentiriam mais preparados para fornecer uma prática docente transformadora e promotora de uma maior integração entre os alunos, na construção do seu próprio conhecimento.

Sobre a atualização do currículo e do Projeto Político Pedagógico (PPP) da escola no contexto do ensino remoto, os professores responderam que nenhum documento foi atualizado, mas que foram realizadas reuniões, para discutir possíveis mudanças e adaptações documentais, dada a importância que esses documentos exercem na orientação das ações da escola e da prática pedagógica docente. Vale salientar que, no tocante a atualização desses documentos, é imprescindível que a escola considere por base os documentos oficiais da educação, como a Lei de Diretrizes e Bases da Educação Nacional (LDBEN/96) (BRASIL 1996), a Base Nacional Comum Curricular (BNCC) (BRASIL, 2018) e as Diretrizes Curriculares Nacionais Gerais da Educação Básica (BRASIL, 2013) que estabelecem diretrizes básicas de como a escola deve promover o ensino.

Assim, levando-se em consideração o contexto pandêmico e as competências gerais que se apresentam frente às possibilidades de uso de tecnologias na educação, encontramos os seguintes registros na BNCC: valorização e utilização do conhecimento digital, criação de soluções tecnológicas a partir de diferentes áreas, utilização de diferentes linguagens (à exemplo da digital), e forma de compreender, utilizar e criar TDIC de forma crítica, reflexiva, significativa e ética (BRASIL, 2018).

Sobre o planejamento das aulas remotas, os professores afirmaram que tem buscado adequar os conteúdos escolares à realidade dos estudantes, considerando a possibilidade de acesso ou não, por parte deles, aos recursos e meios tecnológicos necessários à participação das aulas 
síncronas e assíncronas. Apesar disso, e de acordo com os dados coletados na pesquisa, $22 \%$ dos estudantes não estavam conseguindo realizar as atividades com recursos próprios ou com apostilas disponibilizadas pela escola, pois não possuiam acesso à internet nem dispunham de celulares ou computadores para participação das aulas e envio das atividades.

Segundo Caetano, Junior e Teixeira, “em tempos de pandemia, torna-se necessário refletir sobre as possibilidades de acesso à internet e, principalmente, sobre as condições que os/as estudantes possuem para acessar a rede" (2020, p. 124). Com isso, deve-se considerar tal realidade, uma vez que impera na sociedade brasileira uma desigualdade social enorme que ainda precisa ser avaliada.

Em relação à prática docente durante o ERE, os professores da Escola Municipal de Ensino Fundamental José Ribeiro Bessa disseram que estavam trabalhando com material impresso (apostila) e utilizavam o Whats $A p p$ para mediação das aulas remotas. Assim, 28\% afirmaram fazer uso do Whats $A p p$ como recurso útil na explicação de atividades escolares, efetivadas através do envio e do recebimento de áudios e/ou fotos entre docentes e discentes, 50\% optaram pelo Whats App e outras ${ }^{11}$ plataformas digitais para disponibilizar arquivos em PDF/Word ou vídeos explicativos, e $22 \%$ afirmaram utilizar materiais impressos, Whats $A p p$ e plataformas de ensino, como o Google meet, para promover aulas síncronas (on-line) pelo menos duas vezes por semana.

Assim, dos vários recursos utilizados pelos professores, no período pandêmico 2020-2021, notou-se que o Whats App foi a opção mais frequente, na Escola Municipal de Ensino Fundamental José Ribeiro Bessa, sendo esta também a realidade de muitas outras escolas públicas brasileiras (CAETANO, JUNIOR, TEXEIRA, 2020).

De acordo com uma pesquisa realizada entre janeiro e fevereiro de 2021, divulgada pelo Parecer $\mathrm{CNE} / \mathrm{CP} \mathrm{n}^{\circ}$ 6, durante o ensino remoto, as redes de ensino municipais utilizaram com maior frequência o material impresso $(95,3 \%)$ e o Whats $A p p(92,9 \%)$. Em terceiro e quarto lugar, são indicados a gravação de videoaulas e as orientações on-line por intermédio de aplicativos. Além disso, também constatamos na pesquisa, o que constitui um fator limitador para o desenvolvimento das atividades realizadas de forma remota, que 48,7\% dos estudantes possuem dificuldades de acesso à internet e 40\% necessitam de adequações de infraestrutura (BRASIL, 2021a).

O cenário para a continuidade do ERE, entretanto, não é nada otimista. O uso excessivo de recursos tecnológicos e aplicativos digitais, como o Whats App, trouxeram para os professores uma sobrecarga de trabalho, demandando o acúmulo de atividades e o cumprimento de agendas fora do tempo de serviço. Assim, a precarização do trabalho docente, evidenciada no contexto do

${ }^{11}$ A exemplo do Loom, ADV Screen, Google apresentações, Google forms e aplicativos variados para edição e gravação de vídeos. 
ERE, as desigualdades refletidas na ausência de acesso à internet e outros recursos pelos estudantes, assim como a necessidade de adaptação e superação aos desafios provocados pelo ensino remoto, demanda reflexão, produção do conhecimento e indicação de alternativas viáveis para a construção de um novo panorama educacional brasileiro.

Sobre o desenvolvimento de atividades com os alunos, envolvendo recursos oferecidos pela escola (apostilas impressas), 22\% dos professores disseram que não estão conseguindo realizálas somente com os materiais disponibilizados pela instituição. Além disso, apontaram que a falta de recursos e meios tecnológicos por parte dos estudantes dificulta o acesso e o acompanhamento das aulas remotas. Como registra a Professora K: "muitos [estudantes] não possuem condições para ter um celular próprio ou uma internet boa para ter acesso às explicações das atividades e, às vezes, não vão pegar as atividades impressas na escola”.

A respeito dessa realidade, é importante resgatar as reflexões tecidas por Cenci e Santinello (2009) que afirmam ser a discriminação e a exclusão social, conceptualizada como um tipo de analfabetismo tecnológico, um dos aspectos desencadeadores da falta de acesso às tecnologias. Isso requer dos governos municipais, estaduais e federais, a implementação de políticas e programas públicos educacionais que proporcionem a oferta de uma educação de qualidade a todos, com acesso e formação para toda a comunidade escolar no tocante ao manuseio de plataformas digitais e recursos tecnológicos utilizados durante o ERE.

Quanto à perspectiva de ensino pós-pandemia, o que predomina entre os professores que lecionam do $3^{\circ}$ ao $5^{\circ}$ ano da Escola Municipal José Ribeiro Bessa é a possibilidade de retorno do ensino totalmente presencial com a inclusão de recursos tecnológicos no processo de ensino e aprendizagem. 
Gráfico 3 - Perspectiva de ensino pós pandemia da covid-19

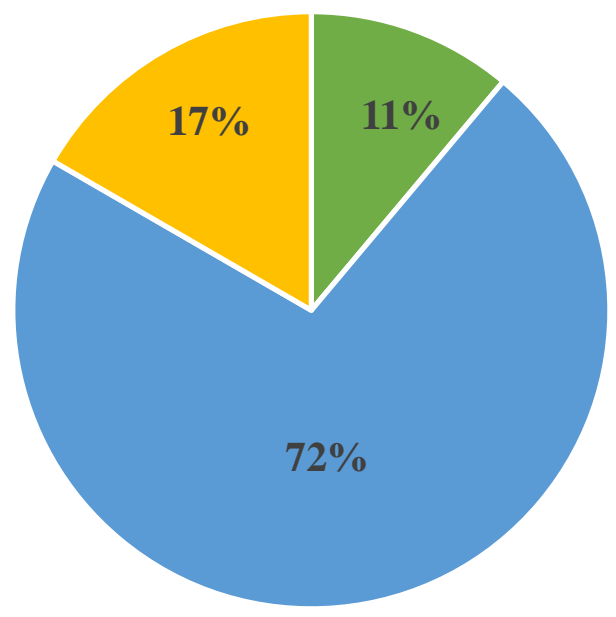

- Ensino totalmente presencial, com aulas de segunda a sexta, se fazendo uso apenas de livro, caderno e quadro no processo de ensino e aprendizagem

- Ensino totalmente presencial, com aulas de segunda a sexta, se fazendo uso de livro, caderno, quadro e também de recursos tecnológicos digitais no processo de ensino e aprendizagem

- Ensino híbrido, combinando atividadespresencias realizadas na escola eatividades virtuais realizadas em casa

Fonte: As autoras, 2021.

Assim, aliado ao ensino presencial, concebem que os ambientes virtuais de aprendizagem poderão estreitar os laços de comunicação entre eles e os estudantes, possibilitando-lhes o acompanhamento no tocante à apropriação do conhecimento escolar. Os professores também afirmaram que se sentem desafiados a promover um ensino que estimule a aprendizagem colaborativa e autônoma dos estudantes, defendendo a adoção de recursos tecnológicos como facilitadores da aprendizagem tanto no ensino remoto quanto no presencial. Não obstante, sentimos a ausência de uma reflexão mais assertiva por parte dos professores com relação às perdas e aos atrasos gerados na educação, em razão de um ensino emergencial (remoto) estabelecido sem a devida preparação estrutural e de formação docente. Em consequência disso, resta-nos indagar, alinhando-se às reflexões tecidas por Sousa Santos (2020), sobre a maneira com a qual esses professores têm utilizado diversas tecnologias, no contexto do ensino remoto, e enfrentado, muitas vezes, a indisponibilidade de conexões em rede, por parte dos estudantes, o cerceamento da liberdade individual de cada um para ensinar e aprender e o medo generalizado provocado pelo inimigo invisível da covid-19.

\section{Considerações finais}

Desde o início de 2020, com a crise sanitária da covid-19, temos observado alterações sem precedentes no âmbito educacional e em todas as instituições e redes de ensino de Educação Básica e Superior no Brasil e no mundo. A situação que se apresentou, particularmente, em nosso país, 
no tocante à suspensão de aulas e ao estabelecimento do ensino remoto ou híbrido, no período de 2020 a 2021, gerou retrocessos no processo educacional e na aprendizagem dos estudantes, além de danos estruturais e sociais para estudantes, professores e toda a comunidade escolar/acadêmica.

Com efeito, o cenário decorrente da pandemia da covid-19 agravou as desigualdades e as fragilidades estruturais de nossa sociedade. Na educação, em particular, ocorreu grande perda de aprendizagem no contexto do ensino remoto quando comparado ao ensino totalmente presencial. Em um relatório lançado em março de 2021, pelo Banco Mundial, sobre a situação da América Latina e Caribe, estimou-se que “o percentual de déficit de aprendizagem no Brasil poderá saltar de 50\% (cinquenta por cento) (nível pré-pandemia) para até 70\% (setenta por cento) num cenário de fechamento das escolas por 13 (treze) meses" (INSTITUTO UNIBANCO, 2021, p. on-line) ${ }^{12}$.

Também como parte dessa desigualdade estrutural, cabe registrar, conforme também nos confirmou os resultados de nossa investigação, a dificuldade de acesso dos estudantes aos recursos e meios tecnológicos durante o ensino remoto. Tal situação os exclui do processo de ensino e aprendizagem e não garante o atendimento de uma educação de qualidade compatível com o desenvolvimento de habilidades, competências e objetivos de aprendizagem previstos na BNCC e nos currículos escolares. Em nosso ponto de vista, se o ensino remoto não tem atendido aos objetivos de aprendizagem de cada um dos anos ofertados pelas instituições de ensino, cabe-nos discutir e propor alternativas de reorganização das atividades educacionais que minimizem os impactos provocados pelas medidas de suspensão das atividades totalmente presenciais nos ambientes escolares.

Ademais, a situação também exige de nós, conforme nos indicou os resultados da investigação, a necessidade de um olhar crítico em relação à inserção do professor na cultura digital no contexto epidemiológico da covid-19. A necessidade de formação, voltada à capacitação desses profissionais, no sentido de lhes fornecer habilidades e competências mínimas para enfrentar os desafios requeridos pelo uso de tecnologias no ERE, tornou-se um imperativo, não apenas evocado pelos professores que lecionam do $3^{\circ}$ ao $5^{\circ}$ do Ensino Fundamental, na Escola Municipal José Ribeiro Bessa, mas de todo o país. A ausência de formação de professores, nessa perspectiva, poderá comprometer a aprendizagem dos estudantes, a qualidade do ensino ofertado e o desenvolvimento do trabalho docente.

A pesquisa que realizamos sinalizou que, apesar dos professores não ter recebido formação adequada ou se sentirem preparados para lidar com ensino remoto, eles se adaptaram a essa

\footnotetext{
12 Para mais informações da pesquisam, confira: https://www.institutounibanco.org.br/conteudo/estudos-estimam-impacto-da-pandemia-naaprendizagem/.
} 
realidade e utilizaram recursos e meios tecnológicos em sua prática docente. De um lado, ao mesmo tempo em que tal situação demanda a urgência de capacitação dos professores por parte das secretarias de educação, dos estados e dos municípios, em colaboração com as políticas e os programas do governo federal, por outro lado, questionamos as condições que inviabilizaram a dignidade do trabalho docente realizado nesse período. O ERE exigiu do professor o acesso a recursos e meios tecnológicos indispensáveis à elaboração do planejamento pedagógico e à ministração de aulas. No entanto, sabe-se que o professor dedica muitas horas para a realização de atividades síncronas e assíncronas, o que compromete a qualidade do ensino ofertado e contribui para a precarização do trabalho docente.

Assim, urge o retorno das aulas presenciais, sendo elas indispensáveis para assegurar o direito dos estudantes, dos professores e de toda a comunidade escolar/acadêmica a uma educação de qualidade. A Resolução CNE/CP n ${ }^{\circ}$ 2, de 5 de agosto de 2021, por sua vez, já manifestou as orientações necessárias quanto ao retorno das aulas presenciais, a partir da data de sua publicação, e a Escola Municipal José Ribeiro Bessa, em particular, tem ofertado o ensino híbrido desde o mês de setembro. Sendo assim, entendemos ser imprescindível que as escolas e as instituições de Ensino Superior cumpram estas e outras medidas sanitárias e pedagógicas, e que seja célere o processo de vacinação dos profissionais de educação, dos estudantes e de suas famílias (BRASIL, 2021).

\section{Referências}

BARDIN, Laurence. Análise de conteído. Tradução: Luís Antero Reto; Augusto Pinheiro. São Paulo: Edições 70, 2016.

BEHRENS. Marilda Aparecida. Projetos de aprendizagem colaborativa num paradigma emergente. In: MORAN, José Manoel; MASETTO, Marcos T.; BEHRENS, Marilda Aparecida. Novas tecnologias e mediação pedagógica. 21ª ed. rev. e atual. Campinas-SP: Papirus, 2013.

BRASIL. Diretrizeses Curriculares Nacionais Gerais da Educaşão Básica. Brasilia: MEC, SEB, DICEI, 2013. Disponível em: http://portal.mec.gov.br/docman/julho-2013-pdf/13677-diretrizes-educacao-basica2013-pdf/file. Acesso em: 19 jul. 2021.

BRASIL. Ministério da Educação. Base Nacional Comum Curricular. Brasilia, 2018. Disponível em: http://basenacionalcomum.mec.gov.br/images/BNCC_EI_EF_110518_versaofinal_site.pdf. Acesso em: 19 jul. 2021.

BRASIL. Parecer CNE/CP n ${ }^{\circ}$ 5, de 28 de abril de 2020a. Ministério da Educação. Disponível em: http:/ / portal.mec.gov.br/index.php?option $=$ com_docman\&view $=$ download\&alias $=145011$-pcp00520\&category_slug=marco-2020-pdf\&Itemid=30192. Acesso em: 19 jul. 2021.

BRASIL. Parecer CNE/CP n ${ }^{\circ}$ 15, de 6 de setembro de 2020b. Ministério da Educação. Disponível em: http://portal.mec.gov.br/docman/outubro-2020-pdf/160391-pcp015-20/file. Acesso em: 19 jul. 2021. 
BRASIL. Lei número 9.394/1996, de abril de 2020c. Lei de Diretrizes e Bases da Educação Nacional. Ministério da Educação. Disponível em:

https://www2.senado.leg.br/bdsf/bitstream/handle/id/572694/Lei_diretrizes_bases_4ed.pdf?sequenc e=1\&isAllowed=y. Acesso em: 19 jul. 2021.

BRASIL. Parecer CNE/CP n ${ }^{\circ}$ 6/2021, de 6 de julho de 2021a. Ministério da Educasão. Disponível em: http://portal.mec.gov.br/index.php?option=com_docman\&view=download\&alias=195831-pcp00621\&category_slug=julho-2021-pdf\&Itemid=30192. Acesso em: 19 jul. 2021.

BRASIL. Resolução CNE/CP nº 2/2021, de 5 de agosto de 2021b. Ministério da Educação. Disponível em: https:/ /www.in.gov.br/en/web/dou/-/resolucao-cne/cp-n-2-de-5-de-agosto-de-2021-336647801. Acesso em: $10 \mathrm{dez} .2021$.

CAETANO, Marcio; JUNIOR, Paulo Melgaço Silva; TEIXEIRA, Tarciso Manfrenatti de Souza. Educação em tempos de pandemia: reflexões sobre políticas de educação na cidade do Rio de Janeiro. Revista Interinstitucional Artes de Educar. Rio de Janeiro, v. 6 - n. Especial, p. 116-138, jun. /out, 2020.

DIAS, Érika; PINTO, Fátima Cunha Ferreira. A Educação e a Covid-19. Ensaio: aval. pol. públ. Educ., Rio de Janeiro, v.28, n.108, p. 545-554, jul./set. 2020.

ESTADOS brasileiros que decretaram lockdown. São Paulo, 2021. Disponível em:

https://www.melhoresdestinos.com.br/restricoes-estado-brasil-quarentena.html. Acesso em: 29 jun. 2021.

INSTITUTO UNIBANCO. Estudos estimam impacto da pandemia na aprendizagem. Minas gerais, 2021. Disponível em: https:/ / www.institutounibanco.org.br/conteudo/estudos-estimam-impacto-dapandemia-na-aprendizagem/. Acesso em: 16 jul. 2021.

JUNQUEIRA, Eduardo. Não se pode confundir educação. Rio de Janeiro, 2020. On-line: ejunqueira. Disponível em: https://www.facebook.com/login/?next=https $\% 3 \mathrm{~A} \% 2 \mathrm{~F} \% 2 \mathrm{Fwww}$.facebook.com $\% 2 \mathrm{Fejunqueira} \% 2 \mathrm{~F}$ posts $\% 2 F 10223345672096526$. Acesso em: 15 jun. 2021.

MARCONI, Marina de Andrade; LAKATOS, Eva Maria. Fundamentos de metodologia científica. 5. ed. São Paulo: Atlas, 2003.

MARTINS, Vivian; ALMEIDA, Joelma. Educação em tempos de pandemia no Brasil: saberesfazeres escolares em exposição nas redes e a educação on-line como perspectiva. Revista Docência e Cibercultura. Rio de Janeiro, 2020.

MINISTÉRIO DA SAÚDE. Vacinômetro. Brasília, 2021. Disponível em: https://www.gov.br/saude/pt-br/vacinacao?. Acesso em: 29 jun. 2021.

MINISTÉRIO DA EDUCAÇÃO. CNE aprova diretrizes para escolas durante a pandemia. Brasília, 28 abr. 2020. Disponível: http://portal.mec.gov.br/component/content/article?id=89051. Acesso em: 29 jun. 2021

PALÚ, Janete; SCHÜTZ, Jenerton Arlan; MAYER; Leandro. Desafios da educação em tempos de pandemia. Cruz Alta: Ilustração, 2020. 
PORTAL DO GOVERNO BRASILEIRO. Serviços considerados essenciais. Brasília, 20 mar. 2020. Disponível em: http://www4.planalto.gov.br/legislacao/imagens/servicos-essenciais-covid-19. Acesso em: 29 jun. 2021.

SAMPAIO, Marisa Narcizo; LEITE, Lígia Silva. Alfabetização tecnológica do professor. 10. ed. Petrópolis, RJ: Vozes, 2013.

SECRETARIA DE EDUCAÇÃO E DESPORTO. Nota Técnica nº 01/2021. Mataraca, 2021.

SOUSA SANTOS, Boaventura de. A cruel pedagogia do vírus. Coimbra: Edições Almedina, 2020. 